\title{
Black Lives Matter and Granger Causal Testing: A Signal of Economic Deprivation
}

\author{
Jacob Gifford ${ }^{1,2}$, Jeffrey Oliver ${ }^{1}$ \\ ${ }^{1}$ Department of Sociology, Brigham Young University-Idaho, Rexburg, USA \\ ${ }^{2}$ Department of Economics, Brigham Young University-Idaho, Rexburg, USA \\ Email: gif16004@byui.edu, oliverj@byui.edu
}

How to cite this paper: Gifford, J., \& Oliver, J. (2021). Black Lives Matter and Granger Causal Testing: A Signal of Economic Deprivation. Modern Economy, 12, 1666-1685.

https://doi.org/10.4236/me.2021.1211084

Received: October 3, 2021

Accepted: November 26, 2021

Published: November 29, 2021

Copyright $\odot 2021$ by author(s) and Scientific Research Publishing Inc. This work is licensed under the Creative Commons Attribution International License (CC BY 4.0).

http://creativecommons.org/licenses/by/4.0/ (c) (i) Open Access

\begin{abstract}
BlackLivesMatter (BLM) protests achieved historically high rates of participation in 2020, resultant of social and economic distress. This study observes the effect of strain through both a collective action framework and statistical methodology. Withstanding the departure of new social movement theories from the traditional paradigm, we apply an economic lens to understand the underlying strain on the BLM population. The Google Trends API and Granger Causal testing demonstrate that the outlying 2020 increase in social movement participation is predicated on the COVID-19 pandemic. There were significant short-run economic effects, namely, the misallocation of resources and labor market disequilibrium on the Black community. Our analysis additionally demonstrates the discrepancies between variable search rate increases and changes in their real counterparts. With all other contributing factors held constant, we find significant causal relationships towards BLM search rates, implying a directional propagation of pandemic-related socioeconomic forces and the resulting social movement participation, signaling economic deprivation.
\end{abstract}

\section{Keywords}

BLM, Granger Causality, Social Movements

\section{Introduction}

Over the past ten years, there have been events of racial injustice, police brutality, and division among communities within the United States. We saw the response and outcries that unfolded from those moments and wrestled with the moral underpinnings of desperate times. Numerous occurrences in the 20102020 decade allowed the BlackLivesMatter (BLM) movement to gain traction, until 2020 the world had yet to see a significant economic crisis, and global pan- 
demic cumulatively lead to an exponential response in BLM interest and search participation.

The Granger causal econometric model contained in this research displays the temporal effect that precipitating economic factors had on the BLM movement. Under controlled assumptions in our model, value-added and collective action theory qualify these causal flows from exogenous economic and social forces towards exponentiated search participation (volume of browser interest searchesassumed to maintain a fixed proportion to real participation, therefore an accurate measure of changes in participation). These frames of reference allow us to interpret the BLM social phenomena as a signaling mechanism of economic strain. Observing the economic distribution of scarce material ends is a lens to further piece together the complex social puzzle of equality, race, cohesion, and cultural identity amid crisis.

It is duly noted that the individual experiences within the BLM population are unique. We explored the dynamic movement as a whole in its interaction with the economic factors believed to be implicated. This effort stands as a perspective that breaches the surface of professed grievances of racial disparity to clarify what discretely contributed to the outbursts of racial tension seen by even the most casually informed. We sought to avoid the perception of negligence regarding the empathic motivators underlying social distress. It is sincerely understood that the data tell a story of actual events that have unfolded, and within those statistics lie individuals, families, and communities who feel the daily effects of the disparities that grow between us all.

The institutional sociological thinker C. Wright Mills (1959) wrote, "you can never understand an individual unless you also understand the society, historical period in which they live, personal troubles, and social issues." We hoped that within this maxim, we could find empathy for the BLM movement.

The main contribution of this research pertains to furthering our insight into casual relationships between social forces and their predicated movements as well as the demonstration of the feasibility for sociological research to employ econometrics and other interdisciplinary methodologies for gaining insight into macro level forces affecting social trends. Given this, the assumptions under these models can often be reductional, lacking nuance and precision.

The structure of this paper is organized as follows: We begin with a historical background, and introduce our conceptual model. We then move into the various components of the model and relate it to current literature, as well as tie them into our thesis. We then address our question using granger testing methodologies to understand why BLM search participation grew at unprecedented rates during 2020 .

\subsection{Brief History of BLM}

The collective behaviors defined by generalized ideologies form rather precariously between individual circumstances and broad value narratives. The BLM campaign can be explained as an ideological reconstitution of the value and 
norm systems that within, each participant is led to feel deprived.

BLM is specifically targeted towards the restoration of justice and equality among marginalized groups, in the Black community. BLM's decentralized framework directly opposes police brutality, and more generally, all other forms of systemic oppression, laws, and policies. It should be noted that a high level of objectivity was given to the movement per the sociological approach (Black Lives Matter Los Angeles Chapter, 2020).

The BLM narrative began when Trayvon Martin's life came to an end in February 2012. The 17-year-old had been fatally shot by George Zimmerman. In the wake of the decisions made by the federal courts and the state of Florida following the acquittal of Zimmerman, a coalition was formed by self-proclaimed "radical Black organizers" as a platform to campaign and protest against the "state-sanctioned violence" they felt they had seen and experienced in their community (Black Lives Matter Los Angeles Chapter, 2020).

A concise, sympathetic analysis of the BLM framework can be found in Lebron (2017) for additional background on the movement. The number of fatal incidents that followed Martin's death would further solidify the generalized belief that began circulating these befallen communities; that action was necessary against the injustices that had seemingly evolved. This epoch of progression had developed into a perceived societal movement away from the institution of systemic group prejudice. Christopher Lebron (2017: p. xiii), professor of political philosophy at John Hopkins University, wrote that from his point of view, "BLM represents a civic desire for equality and a human desire for respect. "Their emphasis on inclusion, diversity, and empathy resonates with their statement that "to love and desire freedom and justice for ourselves is a prerequisite for wanting the same for others." This ideology has certainly given mobilizing power to their cause (Black Lives Matter Los Angeles Chapter, 2020).

We emphasize through Smelser's collective action theory that protesting acts as a signaling mechanism of social strain. Past evidence of protest implies that enough stress on the societal fabric has been present that a societal movement was necessary for reconstituting some ideal or concessionary state. Under this same framework, we developed a conceptual understanding of precisely how the strain from economic deprivation and COVID led to social movement participation. Moreover, that certain conditions beyond what was ostensibly portrayed contributed to such.

\subsection{Conceptual Model}

Strained groups in society seek reconstitution and therefore mobilize under generalized beliefs. Under conditions of historical consequence, Black communities have generally been exposed to a vastly different social experience in America than their white counterparts (Smelser, 1965: p. 384; Lebron, 2017).

Neil Smelser's value-added theory (Smelser, 1965) explains how unsettled grievances from strain form generalized beliefs and develop into social action. Strain is defined as an inadequate social regulation that destructs an individual's 
perception of themselves, their facilitatory resources, and opportunities (Smelser, 1965: pp. 15-16). The value-added theory of collective behavior argues that individuals join radical social movements because of this experienced effect (Smelser, 1965: p. 71).

Smelser developed this theoretical framework to analyze exogenous forces and their "value-added" or contributing, cumulative effect on movement in society. Given a specific social trend or collective behavior, a traceback through the added social factors of strain allows scholars to identify the formation, spread, and mobilization of a movement and its ideology (Smelser, 1965: p. 23). The fundamental construct of social action is centered around the values that these groups within society uphold. Collective behavior stems from generalized belief systems that frame identities, goals, and values within.

The theory of collective behavior (Smelser, 1965: pp. 26-28) defines four criteria in which Smelser argued social action finds its root and by which it might be interpreted. Values in this framework are the basis for "social system integration and institutionalized action." Group's values validate the behavior occurring on the individual level. Norms regulate the realization of these values to allow for ideologies to spread and movement to progress relatively free from conflict. Roles specify the structural organization that mobilizes people towards these values within social norms. Lastly, Situational facilities are the means and resources utilized in actualizing these goals for the welfare and progress of the group (Smelser, 1965: p. 28). Due to strain placed on any aspect of these components of social behavior, outbursts in various forms often develop that seek to reconstitute the strained systems (Smelser 1965: p. 28).

\subsection{Structural Conduciveness}

As a pre-qualifier to outbursts of collective action, structural conduciveness dictates "the degree to which any structure permits a given type of collective behavior" (Smelser, 1965: p. 384). The consideration of the social systems-Values, norms, organizations, and facilities that enable or inhibit the progression of such movement is vital in any explanatory process of social organization. Conceptually, conduciveness acts as a platform that initiates the transformation of potential social energy into collective action.

The publicized events of violence and reported oppression towards Black individuals over the decade catalyzed the rise of dissent in the years that followed 2012. Individual experiences such as those from Michael Brown or George Floyd come to mind when discussing the effects of race and racial prejudice. We must understand these events to grasp what conditions were necessary to prime the state of unrest that amounted in 2020.

The product of a conducive state is the increased probability of a succession of value-added factors (Smelser, 1965: p. 135). Systems in unstable conditions might introduce panic and hysteria in response to strain, furthering the process towards mobilization while stable structures minimize the perceivable threat and limit the incentives for social action. Smelser (1965: pp. 139-140) discusses these 
ideas and how the possibility of communication significantly alters a movement's ability to spread formulated ideologies and beliefs-a fundamental component of conduciveness. Boulianne (2015) described the role that social media played in the active spread of belief systems throughout broad communities. Though the effect of social media on BLM ideological spread was ostensibly evident, the outcome was momentous.

Social media acts as a conduit for the rapid transfer of information across large populations and geographies. Under certain climates, it becomes a forum for argumentative pathos and public hysteria. If these ideological channels were hypothetically not accessible, the spread of generalized beliefs would be difficult to propagate at the level and speed seen today. This assumption implies two crucial elements to the context of the research undertaken here. First, we can attest with reasonable confidence that these avenues are, in part, the foundation for collective behavior and social movement. Furthermore, we can quantify the effect of the immediate forces of economic and social disparity and the impact that the perceptions of these topics have on BLM interest queries as a secondary consequence. An empirical approach later discussed displays how we utilized this relationship to further our understanding of the ideological spread of BLM.

\subsection{Structural Strain}

"Social movements develop to reassure members that action is being taken to address strain, grievances, and deprivation" (Weeber \& Rodeheaver, 2003). J-Curve theory, introduced by James Davies (1962) and further discussed by Miller, Bolce, and Halligan (1977), explains that revolting behavior occurs when a steep decline or reversal follows a period of progress, welfare, justice, or other measures of social equality. From Davies' (1962) theory, it could be construed that a disparity in itself will not always add significant levels of strain to an affected group, but instead that a welfare trend's rate of divergence relative to the whole can alter the perception of the deprived group, i.e., the felt or relative deprivation.

To further explore this phenomenon, consider how this concept of relative deprivation affects SMP. If participation was to be solely affected by structural conduciveness; then, it would be difficult to clarify why various time frames produce different rates of social movement participation (SMP). For example, ACLED $(2019 ; 2021)$ reported that the composited 2019 social protests (including, but not limited to BLM, LGBTQ+, and Women's Rights demonstrations) yielded less than one-third of the total number of specific BLM protests for 2020.

Therefore, the discrepancy of protest rates between years must be explained by a heightened impact on BLM group members through added factors. Smelser reiterates this when he affirms that conduciveness, strain, and even generalized beliefs are frequently not enough to spur SMP (Smelser, 1965: p. 147). Current Social structures have shaped the way that COVID was able harm minorities at a disproportionate rate during 2020. Resource deprivation resultant of the pandemic prevented millions from gaining access to necessary goods and services 
that could ensure their welfare. McCarthy and Zald (2001) built upon this by describing that social movements arise when groups or individuals in society "feel that they are deprived of a specific good, service, or resource." In line with Davies (1962) reasoning, a fundamental aspect of the regarded level of strain is that actual deprivation is convoluted inside perceptions of disparity. It seemed to become an issue of relative, more so than absolute deprivation that determined SMP. Strain presented itself in the form of a deadly pandemic in 2020, though it has taken many other forms over the years. Social and economic forces are core features of COVID's specific impact on the BLM movement.

\subsection{Economic Strain}

The Organization for Economic Cooperation and Development (2020) published a report on the aggregate toll that COVID has placed on world macro economies, calling it a supply shock, in line with short-run Neo-Keynesian modeling. The bureau of labor statistics (2020) reported a total annual decrease in national income of 32.9 percent in the second quarter of 2020-the worst quarterly decline in recorded history. The sizeable losses of 2020 and what occurred in the 2008 financial crisis are effectively similar, disparaging workers and firms alike (Krugman, 2020).

In one particular computable general equilibrium (CGE) model, Exogenous supply shocks were designed to affect macroeconomic behavior across sectors. One empirically supported COVID-19 simulation enacted a complete supply shock on 50 percent of the sectors in the economy. The resultant effect described collapsed sectors and labor demand not being met. As firms exited, job destruction accelerated, leaving many without the necessary goods and services required for consumption and employment within those industries. The state of the economy was ultimately left asymmetrically shrunken, with the multiplied forces affecting demand more significant than the original supply shock (Guerrieri et al., 2020).

Due to the public health response and the efforts to lessen the impact on scarce resources, large measures were taken to ensure the functionality of these systems. As a trade-off, the attempts to flatten the infection curve proved to heighten the effects of the recession. Even with additional fiscal policy approaches taken by the federal government at the cost of trillions, the economy was nevertheless left with its short-run output far below its potential trajectory. The efforts to resolve the implications of COVID had been grossly undercut by inefficiency (Gourinchas, 2020). These asymmetrical supply shocks are supported in Fischer's general equilibrium model. He found that shocks from disturbances in aggregate demand tend to cause further unemployment (Fischer, 1985). As a result of this unemployment shock, the data show an unequal share of the economic stressors shafted toward the black population, devastating many living in or near poverty (US Bureau of Labor Statistics, 2020).

Disproportionately, black groups working predominantly in the service sector, industrial, or other high-risk work settings experienced greater unemployment rates and more extensive economic deprivation. Significantly higher unemploy- 
ment rates for black individuals were reported as evidence of this sectoral disparity (US Bureau of Labor Statistics, 2020). As these jobs were dissolved, unemployment tended towards these sectors such that black communities experienced deprivation en masse (Abel and Deitz, 2021). Sitler (2020) pointed out the clear indication of overall strain on the black community regarding public health and economic deprivation. This stress not only affected the physical states of people but their perceptions also.

\subsection{Generalized Ideologies of BLM}

Social movements form in reassurance to their participants that action is being taken to reconstitute the strained system. Aside from economic stress, attention was drawn to perceived inequalities in justice systems and supposed equality available to all. Polarizing deaths and alleged mistreatment of individuals in the hands of the law throughout the 2010s and into the current decade cried foul play to those who felt marginalized and lacked control or mobility in socioeconomic conditions. Groups who have felt or at least perceived disdain from larger institutions, systems, or products of such, might naturally grow defensive in response to events they deemed oppressive or exploitative (Roper Center for Public Opinion Research, 2020; Weeber and Rodeheaver, 2003).

The collapse of the core levels of these social systems due to strain forces the group mentality to naturally look beyond prominent causal elements towards the surrounding systems of norms and values. This process can be the natural path of subjected groups to take on in pursuit of ideological reconciliation (Smelser, 1965: p. 384). The belief of deprivation causes narratives to develop in a generalized form. Though measurable injustice and inequalities exist, groups may over attribute causes of grievances to rudimentary issues while more expansive problems go undetected. Belief systems formed at the general level can often prove inconsistent with the group's specific needs; thus, purported injustices are often only partial insights into group needs. Though BLM's guiding principles are extensive, they fail to address probable causes of disparity and economic oppression stemming from socioeconomic conditions (Black Lives Matter Los Angeles Chapter, 2020).

Social media (SM) played an extensive role in exacerbating the levels of social movement participation in 2020. Anderson (2016) calls it an "instigator of national attention towards black social issues." Black individuals (68 percent) are roughly two times as likely as white individuals (35 percent) to find content regarding race or race relations on their SM feeds. Clustering develops within likeminded communities on social media, communicating similar views (Adamic \& Glance, 2005; Conover et al., 2011; Hargittai \& Walejko, 2008). Social media participation played an active part in spreading belief systems throughout racially and geographically diverse regions, holding especially true for political and ideological mobilization. People saw the far-reaching effect of the ability for social media to connect themselves to these issues (Boulianne, 2015; Freelon et al., 2018). 


\subsection{Watershed Moment}

As stated previously, conduciveness, strain, and even generalized ideologies are not enough to produce collective behavior. A catalyst must incite panic, rage, or hysteria; and prompt emotional responses from the confines of established social regulation (Smelser, 1965: p. 16). George Floyd's death, in many ways, symbolized a manifestation of the generalized fears and ideologies that pervaded these social clusters. It unleashed the anxieties of millions, amassing into search participation and protest (Van Dijcke and Wright, 2020). It therefore might go without saying that the George Floyd incident acted as the primary mobilizing agent in the 2020 George Floyd protests.

\subsection{Mobilization, Elite Appeal \& Social Controls}

Given these circumstances, the probability of mobilization and conflict increased. The availability of resources in the development of BLM were critical in its propagation. When grievances exist, groups may be able to mobilize necessary resources to alleviate perceived strain (Korpi, 1974). From money, labor, social capital, knowledge, support of the media, and political elites, resources have proved essential in helping a movement succeed (McCarthy and Zald, 2001). Resource mobilization frameworks do an excellent job of explaining why specific movements expand and alter society while others struggle to gain access to these tools (Della Porta, 2020). The possibility for these grievances to be addressed is an incentive for SMP; therefore, protesters generally chose the most efficacious behaviors for reaching the movement's goals (Opp, 1988).

The duration of a movement is at the mercy of the responses taken by the institutions of social control. In the pursuit of self-interest, ideological movements such as BLM can be crafted into platforms by public servants for gaining constituent votes. In a similar vein as the mobilization of resources, political potential can be seen as a gain for the movement itself and the policymaker or representative (Freelon et al., 2018).

Election years of 2016 and 2020 produced significant rises in BLM search participation. It seems to reveal another condition of what has led to mass BLM protesting. The prospect of change through a potential candidate seemingly drives much of the movement outbursts that we see.

Freelon et al. (2018) contend in their model of social media efficacy that causality exists between BLM participation and the news coverage of police brutality. This proved to be the "strongest driver" of attention from political institution leaders in elite roles. Because of the incentives involved in campaigns for political leadership, leaders in influential roles can respond to these events to benefit their self-interest and constituents. Elite attention is integral for internal change within institutions. Though movements might spread rapidly outside of the normative structure, change needs to occur systemically for people's lives to improve (Button, 1989). 


\subsection{Theoretical Limitations}

Sen and Avci (2016) mentions that the only indicator that strain was present is the social movement activism that arises. Though this angle is a consistent critique of Smelser's work, The logic of such is deemed inherently circular by many. A framework explaining causality cannot effectively predict all movements. social movements are only observed after they arise and not before, implying potential confirmation bias in this methodology.

Smelser prefaces his work enforcing the notion that formulating causal laws between specific stressors to outbursts and collective action is not a perfect approach to understanding collective outcomes. Rather, within assumed parameters, social stressors can be modeled to discover direct outcomes in SMP (Smelser, 1965: p. 49).

The lasting contribution of "The Theory of Collective Behavior" is its elaboration of the components of collective behavior. Though it fails to address the nuance in the spectrum of collective action, the tenets proved adequate for supporting this research.

As Smelser says himself, any sociological analysis approach is "incomplete, limited, incapable of answering certain problems, and perhaps even incompatible with the others." He draws on various theoretical perspectives throughout his book while maintaining accuracy towards his intended application (Smelser, 1988).

Note that the primary interest of this paper is not of qualifying proof for every possible contributing factor as a causal force leading to SMP, but to describe how social interests and group ideologies-focused around realized economic phenomena-relate. A critical assumption to emphasize is that there is implied strain when a movement has occurred.

\section{Methods \& Data}

Here we return to the original question of why BLM search participation grew at unprecedented rates during 2020 while it appeared that similar strain factors and mobilizers were present in past years? Using statistical testing, we sought to discover whether causal relationships between COVID, recession panic, and BLM search participation existed and the extent that they interacted with one another.

We are interested in how forceful the social narrative was between individuals and how generalized ideologies might propagate the perception of strain before the factors are initially felt. The study became a test to understand the continued validity of strain theory and emphasize the integral nature of resources and economic inputs in effecting SMP.

\subsection{VAR Model}

A vector autoregressive model is a linear approximation of multiple time series in which the values of $y_{t}$ are based on previous periods $y$ of and $x$ (Bose, Hravnack, and Sereika, 2017). 


$$
\left[\begin{array}{l}
y_{t} \\
x_{t}
\end{array}\right]=\beta_{0}+\beta_{1}\left[\begin{array}{c}
y_{t-1} \\
x_{t-1}
\end{array}\right]+\left[\begin{array}{l}
\varepsilon_{y t} \\
\varepsilon_{x t}
\end{array}\right]
$$

As seen in Equation (1), $\beta_{0}$ is defined by a matrix of vector constants and $\beta_{1}$ by a matrix of lag coefficients. The "vars" package in R estimates VAR models using OLS per equation (Pfaff, 2018).

\subsection{Granger Regression}

Clive Granger (1969) was awarded the Nobel prize in economics for his contribution of the statistical technique known as Granger causal regression. Granger testing uses a vector autoregressive model to evaluate whether a time-series $x$, Granger-causes series $y$. If the vector autoregressive model for $y$ as a function of both $x$ and $y$ fits significantly better than $y$ alone, then series $x$ is said to granger-cause series $y$. (Arnold, Yiu, \& Abe, 2007)

One might say simply that time series $A$ predicts time series $B$ better than $B$ could predict itself. Granger-causality might be better interpreted as a temporal relation rather than a causal one (Thurman \& Fisher, 1988; Granger, 1969). Granger symbolizes this "causal" relationship by noting that $X \rightarrow Y(X$ causes $Y)$ (Granger, 1969). Once stationary, the VAR model is compared to the singular series, and like gears, the test measures the ability for them to mesh at various time intervals called lags.

$$
\begin{gathered}
y_{t} \approx A \cdot y_{t-1}+B \cdot x_{t-1} \\
y_{t} \approx A \cdot y_{t-1}
\end{gathered}
$$

Equations (1) and (2), display a simplified expression of the dependent relationship in the VAR model, where $A$ and $B$ are coefficient matrices (Granger, 1969; Arnold, Yiu, \& Abe, 2007).

Utilizing VAR models in Granger testing assumes stationarity of data. Use of the Augmented Dickey-Fuller test observes the existence of unit roots in time series. The rejection of $H_{0}$ states that no unit roots exist and that the series is stationary (Hamilton, 1994; Hafner \& Herwartz, 2009; Venables \& Ripley, 2002; Zeileis, 2006).

\subsection{Data and Time Series Objects}

We sought to measure the level of social movement search participation during 2020 at different periods. Physical protest data was collected from the Armed Conflict Location and Event Data Project (ACLED, 2020). Time series data used in Granger testing were collected using a Google Trends API within R Studio. Additionally, COVID-19 Case count series were collected through the Center for Disease Control. For further information on COVID and CDC methodology, consult the Center for Disease Control and Prevention (2021).

The data sources were selected to further our understanding between the perceived deprivation and the real impact of COVID-related stressors on BLM par- 
ticipation rates, including COVID cases and COVID searches. Additional data for descriptive observation came from BLS and Federal Reserve Economic Data (FRED), as noted in Table 1. More information on BLS and federal reserve methodology can be found (FRED, 2020; FRED IC, 2020; FRED UR, 2020; US Bureau of Labor Statistics, 2020).

Trends is a public platform provided by Google for the aggregation of browser queries into scaled indexes by relative volumes and search categories. It accounts for the daily internet habits of Google's users. By specifying a keyword, geographic region, and time range, the resource gathers the performance statistics of that topic or area of interest into a frame of dates and index levels. The data is normalized to a consistent search population base and scaled to a range between 0 and 100 respective of the individual sample sizes. Trends provide social data that stands apart from other APIs. The breadth of Google's browsing market share and the methodological validation received in recent literature provide a reason for its use in addressing the challenges faced by the complexities of BLM research. A thoroughly established link exists between internet search patterns

Table 1. Time series data.

\begin{tabular}{|c|c|}
\hline Time Series & Summary \\
\hline BLM Searches & $\begin{array}{l}\text { Google Trends results for searches of "BlackLivesMatter" } \\
\text { and related terms beginning January 1, } 2020\end{array}$ \\
\hline COVID Searches & $\begin{array}{l}\text { Google Trends results for searches of "COVID-19" } \\
\text { and related terms beginning January 1, } 2020\end{array}$ \\
\hline Unemployment Searches & $\begin{array}{l}\text { Google Trends results for searches of "unemployment" } \\
\text { and related terms beginning January 1, } 2020\end{array}$ \\
\hline Floyd Searches & $\begin{array}{l}\text { Google Trends results for searches of George Floyd } \\
\text { and related terms beginning January 1, } 2020\end{array}$ \\
\hline COVID Cases & $\begin{array}{l}\text { Center for Disease Control published cases in } \\
\text { The United States beginning January 1, } 2020\end{array}$ \\
\hline${ }^{\star}$ FRED Unem \% & $\begin{array}{l}\text { FRED data on unemployment rates beginning January } 1 \text {, } \\
2020\end{array}$ \\
\hline${ }^{\star}$ FRED Black \% & $\begin{array}{l}\text { FRED data on unemployment rates by race beginning } \\
\text { January } 1,2020\end{array}$ \\
\hline${ }^{\star}$ FRED White $\%$ & $\begin{array}{l}\text { FRED data on unemployment rates by race beginning } \\
\text { January } 1,2020\end{array}$ \\
\hline${ }^{\star}$ FRED ICSA & $\begin{array}{l}\text { Weekly Initial claims for unemployment insurance } \\
\text { beginning January 1, } 2020\end{array}$ \\
\hline *BLM July 2016 & $\begin{array}{l}\text { Google Trends resulted for searches of } \\
\text { BlackLivesMatter (BLM) in July } 2016\end{array}$ \\
\hline${ }^{\star}$ Ten Year BLM & $\begin{array}{l}\text { Google Trends 10-year overview of searches of } \\
\text { BlackLivesMatter (BLM) }\end{array}$ \\
\hline
\end{tabular}

Note: *series not used in Granger regression. 
and behaviors within advanced socioeconomic conditions (Carrière-Swallow \& Labbé, 2011).

Some of the challenges of more bureaucratized data sources are that sampling frequencies are usually too low for precise evaluations of social narratives that unfold in days instead of months. Though crucial ideas can be drawn from longterm data, a sharper tool is required for specific trends in social movement. Research on the validity of Trends analyses can be found in (Jacobson \& Choi 2008; Carrière-Swallow \& Labbé, 2011; Suhoy, 2009).

We tested the effects of COVID searches, COVID cases, unemployment searches, and Floyd searches on the SMP rate. Table 1 provides descriptions of the datasets used in our qualitative analysis and statistical regression. Table 2 provides the differenced time series descriptive statistics.

\subsection{Granger Model}

In estimating a VAR model for the time series in use, the issues of stationarity arose. First-order differencing corrected for this (Suhoy, 2009). We tested for unit roots with the differenced series using the Augmented Dickey-Fuller test. We found the test statistic to be significant $\alpha<0.01$ on all VAR series at lags of 6 , therefore we rejected the null hypothesis that a unit root existed (Mushtaq, 2011; Hyndman and Athanasopoulos, 2018). As stated previously, the lag time in temporal regression refers to the time interval in which the series is lagged from each other to create a closer fit in growth trends. In the example of sampling rates for our time series, a lag time of $\mathrm{n}$ refers to a difference in $\mathrm{n}$ day between the VAR and singular series' positional alignment on the $\mathrm{x}$-axis.

We used the "vars" package in R to estimate a VAR model using OLS methodology. Our program looped through 50 lag periods for all possible combinations of the time series objects and returned the F-statistic, p-value, Critical F-statistic, Durbin-Watson statistic, Akaike Information Criterion, R-squared, Degrees of Freedom, Autocorrelation factor, and ACF interval (Pfaff, 2020).

The Akaike Information Criterion (AIC) measures the integrity of the model. It calculates the prediction error. The Durbin-Watson test indicates the serial

Table 2. Descriptive statistics of time series.

\begin{tabular}{cccccccc}
\hline Time Series Model & $n$ & $\bar{x}$ & $\sigma$ & med & skew & mad & kurtosis \\
\hline BLM Search & 279 & 0.051 & 10.954 & 0.000 & 0.190 & 7.060 & 4.597 \\
COVID Searches & 279 & 0.079 & 5.905 & 0.000 & -0.017 & 4.448 & 1.136 \\
COVID Cases & 288 & 0.263 & 7.591 & 0.000 & -0.143 & 4.061 & 3.853 \\
Unemployment Searches & 279 & 0.201 & 8.030 & 0.000 & 1.179 & 4.448 & 9.807 \\
Floyd Searches & 279 & 0.000 & 4.269 & 0.000 & 4.192 & 0.000 & 44.992 \\
\hline
\end{tabular}

Note: first differences for time series objects to create stationarity and remove stochastic trends; see Table 3 Durbin Watson values. 
autocorrelation level for the residuals for the given lag interval (Penn State, 2020). Additionally, the Auto-correlation factor and the accompanied ACF criteria were included in the loop for different lags. Intervals will also be discussed in the results section.

\subsection{Hypothesis Testing}

Equation (4) demonstrates $H_{0}$ for the Granger Causality Test. $H_{0}$ determines that causality does not exist between the series. We reject $H_{0}$ for a Granger test in which the joint explanatory power of the combined model is significant past the critical value of an $\mathrm{f}$-distribution.

$$
H_{0}: A \nrightarrow B
$$

Table 2 shows the comprehensive list of tested hypotheses. By rejection of $H_{0}$ we assume a causal relationship exists in which,

$$
H_{A}: A \rightarrow B
$$

A robustness test of the Granger model can be found in Rossi and Wang (2019).

\section{Results}

As briefly mentioned previously, an issue that arose was trend stationarity. Leveling the trend lines for each of the time series was necessary to meet the assumptions of the VAR and Granger models. Each test resulted in coefficients for the standard equations to construct the VAR series. Results summaries are discussed below, but Table 3 should be referenced for a comprehensive list of causal relationships and statistical fits. Pay attention to the lag times and R-squared values.

\subsection{Unemployment Effect}

We discovered unemployment search trends to be a preemptive predictor of each test variable in the study. Table 3 shows that public interest in unemployment explains 32.7 percent of the variation in BLM searches five days before the BLM increase. These searches also predicted COVID cases at a lag of 2 days $\left(R^{2}\right.$ $=13.7$ percent $)$ and COVID searches at lag $=10\left(R^{2}=22.26\right.$ percent $)$. We found unemployment searches to predict Floyd search interest similarly to BLM.

\subsection{COVID Effect}

We did not find COVID searches a significant predictor in BLM searches but found causal relationships towards unemployment and COVID cases, which were predictors of BLM rates. We saw COVID search patterns predicting actual case growth at a lag order of 10 days.

Case levels predicted unemployment searches 14 days in advance $\left(R^{2}=51.3\right.$ percent), and searches predicted them three days in advance $\left(R^{2}=14.9\right.$ percent $)$.

\subsection{BLM \& Floyd Effect}

Floyd searches were significant in predicting future BLM searches $\left(R^{2}=91.07\right.$ 
Table 3. Optimal granger tests.

\begin{tabular}{|c|c|c|c|c|c|c|c|c|c|}
\hline $\begin{array}{c}H_{0}: \text { A does not } \\
\text { Granger cause B }\end{array}$ & lag & $p$ & f-stat & df1 & $\mathrm{df} 2$ & $\mathrm{D}-\mathrm{W}$ & Adj. $R^{2}$ & AIC & $\mathrm{ACF}$ \\
\hline UNEM-BLM $^{* *}$ & 5 & 0.0002 & 1.7141 & 5 & 526 & 2.0096 & 0.3274 & 3883 & -0.051 \\
\hline BLM-UNEM & & & & & $H_{0}$ & & & & \\
\hline FLOYD-CVCASE & & & & & $H_{0}$ & & & & \\
\hline CVCASE-FLOYD* & 14 & 0.0395 & 1.7756 & 14 & 472 & 2.0018 & 0.4422 & 3154 & -0.055 \\
\hline UNEM-FLOYD & & & & & $H_{0}$ & & & & \\
\hline FLOYD-UNEM & & & & & $H_{0}$ & & & & \\
\hline UNEM-CVCASE* & 2 & 0.0189 & 3.9996 & 2 & 544 & 2.0262 & 0.1370 & 3757 & 0.012 \\
\hline CVCASE-UNEM $^{* *}$ & 14 & 0.0079 & 2.1752 & 14 & 472 & 2.0071 & 0.5132 & 3484 & 0.007 \\
\hline CVSRCH-CVCASE & 10 & 0.0026 & 2.7497 & 10 & 496 & 2.7497 & 0.1945 & 3408 & 0.008 \\
\hline CVCASE-CVSRCH & & & & & $H_{0}$ & & & & \\
\hline CVSRCH-FLOYD & & & & & $H_{0}$ & & & & \\
\hline FLOYD-CVSRCH & & & & & $H_{0}$ & & & & \\
\hline CVSRCH-UNEM ${ }^{\star}$ & 3 & 0.0348 & 2.8944 & 3 & 538 & 2.0065 & 0.1491 & 3621 & -0.042 \\
\hline UNEM-CVSRCH* & 10 & 0.0403 & 1.9206 & 10 & 496 & 2.0091 & 0.2226 & 3527 & -0.125 \\
\hline BLM-CVCASE ${ }^{\star *}$ & 25 & 0.0097 & 1.8236 & 25 & 406 & 2.0010 & 0.2228 & 3196 & -0.017 \\
\hline CVCASE-BLM & & & & & $H_{0}$ & & & & \\
\hline BLM-CVSRCH & & & & & $H_{0}$ & & & & \\
\hline CVSRCH-BLM & & & & & $H_{0}$ & & & & \\
\hline FLOYD-BLM ${ }^{\star *}$ & 14 & $<0.0001$ & 8.8396 & 14 & 472 & 1.9980 & 0.9142 & 3336 & 0.061 \\
\hline BLM-FLOYD ${ }^{*}$ & 35 & 0.0121 & 1.6691 & 35 & 346 & 2.0089 & 0.6395 & 3104 & -0.028 \\
\hline
\end{tabular}

percent) on a lag order of 5 days. BLM was not found to be causal in relationship to Floyd Searches.

\section{Discussion}

We gained substantial confidence in our estimation of conduciveness through this process. We saw a predictive relationship between COVID and Unemployment searches. As the disease grew rampant, the stress of potentially losing work came to the forefront of a welfare concern. Though real unemployment did not grow to its peak levels until months after the initial boom of Google Trends queries, the flow of information through society was narrating a different story to those who felt at the mercy of the pandemic.

It appears that COVID did not directly predict the rates of BLM interest but instead provided a transfer of social energy into BLM through the devastation of 
the labor resource market, which in turn had a significant effect on all the individual variables in this model, especially BLM.

Nearly one-third of BLM trend rates were predicated on the effects of unemployment, speaking volumes about how on a societal level, the stress involved in turbulent expectations about work is an effective motivator for action.

The formulation of these fears provided a tremendous catalyst to the movement. There is a discrepancy between absolute deprivation and the perception of anticipated deprivation.

Though real strain was present through the initial COVID crisis, the level of perceived strain reflected in the results could very well have been a primary catalyzer of BLM search rates and participation.

Considering this, we saw that the search trends for unemployment and the statistical observations of such directly correspond with peak values occurring in late March and early April, coming as no surprise, but to find a causal relationship in which events from a previous month could prime what was to follow raises many interesting questions.

Of course, the movement required ideological anchoring for people to understand and collect their grievances. The broken system of facilitatory resources required reconstitution and the solution rested with BLM and their proposed guiding principles.

When George Floyd was killed, the prediction for BLM participation increases to follow was sure. All that remained for the movement to succeed was some image of hope that the future could improve. Floyd's searches explaining BLM participation seem to make sense rather than the inverse, showing that Floyd was a watershed event that controls the directionality of social force propagation.

The complete list of our test variables failed to prove causal towards BLM search rates; we still observed important relationships between these variables and furthered the understanding of the interconnected web they reside. We found that many of Smelser's key points held for this analysis of the BLM movement in a quantitative and theoretical approach. One of the emphases of Smelser's writings was his focus on physical resources. Though more recent literature in social movements has shied away from this as being over-simplistic, we drew critical results from this analysis showing otherwise. This model demonstrated the devastating effect that economic depression had on people, enough to seek social change deliberately. The granger model provided a quantified look into the effect size and time frame of these relationships, as well as a look at a previously unquantifiable measure of public interest through search queries.

This research demonstrated how economic factors and the perceptions of such added to the levels of BLM participation we saw in 2020. The power of these findings is that we not only gain insight into the underlying factors of BLM participation, we also see the effects of what economic concessions might do in silencing social movements. When grievances are consoled, the movement often disseminates as it loses clarity within its framing. Future research might explore deeper into the relationships between these variables among other 
social movements.

\section{Model Validation}

We used Floyd searching behavior as an assumed predictor of BLM searches to test the model's viability. COVID cases and searches were also interdependent in causality, given that they alternately explained the other's growth trends.

As a result of Google's imperfect sampling procedures, there is noise in the series in which one standard deviation of data departs 5.8 percent from the mean growth rates in successive data pulls from equivalent periods. Another issue of comparing magnitudes arose. When called, each time series is scaled individually between 0 for the lowest value and 100 for the highest. To address this problem, we group added the test series within one function into the data frames. Trends automatically adjust them about one another. Carrière-Swallow \& Labbé (2013) further address this subject for a more in-depth understanding of Trends usage.

\section{Conclusion}

In the conducive state that we saw, strain tore at the individual and group perceptions of what was deserved and equitable. We found the BlackLivesMatter social movement to be a signal of such occurred stress. The outcries formed a basis for ideological narratives to craft symbols from events and people-representing the inward desires of people who outwardly attempt to communicate their intense emotional states.

From our perspective of the distribution of factors of production, labor market outcomes, and the overall economic welfare of these specific socioeconomic groups, many of the problems BLM participants sought to reconcile at large came from unforeseeable events tied to disproportionate unemployment and partial sector supply socks predicated on COVID-19 shutdowns.

We find this article to be of use in political and academic settings. Firstly, it provides direction into what social stress may be the foundational cause of collective action. In this case, policy makers might focus efforts on ensuring people receive needed services, cash and in-kind transfer payments. By making strategic decisions, more efficient outcomes can be achieved by limiting the loss from excessive spending in other less preventative areas of social welfare i.e., law enforcement.

Secondly, the use of this methodology could be used throughout sociology, including but not limited to social network research, collective action and social movement theory, and the political economy.

The results of this study should only be generalized so far as the sampling will allow. Only the users of Google within the United States exist within our population from which the samples were drawn. Additionally, much of the supporting literature is only applicable to a US population as well. Results may differ widely in non-American countries, especially those that are culturally less Western. 
Nonetheless, our argument parallels the collective action framework established in that holding all else equal intertemporally, the effects of COVID were large enough to cause record unemployment leading to never-before-seen social movement search participation. Without COVID, it would be difficult to estimate just how impactful the alternative value-added factors would have been in producing mass protest rates.

We found that the effects of COVID can be recognized, with reasonable confidence, as the difference between BLM search participation rates in 2020 and years previous.

\section{Conflicts of Interest}

The authors declare no conflicts of interest regarding the publication of this paper.

\section{References}

Abel, J., \& Deitz, R. (2021). Some Workers Have Been Hit Much Harder than Others by the Pandemic. Tech. Rep., Federal Reserve Bank of New York.

Adamic, L., \& Glance, N. (2005). The Political Blogosphere and the 2004 U.S. Election: Divided They Blog. In Proceedings of the 3rd International Workshop on Link Discovery (LinkKDD’05) (pp. 36-43). New York: Association for Computing Machinery. https://doi.org/10.1145/1134271.1134277

Anderson, M. (2016). Social Media Conversations about Race. Tech. Rep., Pew Research Center.

https://www.pewresearch.org/internet/2016/08/15/social-media-conversations-about-r ace/

Arnold, A., Liu, Y., \& Abe, N. (2007). Temporal Causal Modeling with Graphical Granger Methods. In Proceedings of the 13th ACM SIGKDD International Conference on Knowledge Discovery and Data Mining (KDD'O7 (pp. 66-75). Association for Computing Machinery. https://doi.org/10.1145/1281192.1281203

Black Lives Matter Los Angeles Chapter (2020). Guiding Principles. https://www.blmla.org/guiding-principles

Bose, E., Hravnak, M., \& Sereika, S. M. (2017). Vector Autoregressive (VAR) Models and Granger Causality in Time Series Analysis in Nursing Research: Dynamic Changes among Vital Signs Prior to Cardiorespiratory Instability Events as an Example. Nursing Research, 66, 12-19. https://doi.org/10.1097/NNR.0000000000000193

Boulianne, S. (2015). Social Media Use and Participation: A Meta-Analysis of Current Research. Information, Communication \& Society, 18, 524-538. https://doi.org/10.1080/1369118X.2015.1008542

Button, J. (1989). Blacks and Social Change: The Impact of the Civil Rights Movement in Southern Communities. Princeton University Press.

Carrière-Swallow, Y., \& Labbé, F. (2011). Nowcasting with Google Trends in an Emerging Market. Journal of Forecasting, 32, 289-298.

https://onlinelibrary.wiley.com/doi/abs/10.1002/for.1252

https://doi.org/10.1002/for.1252

Carrière-Swallow, Y., \& Labbé, F. (2013). Nowcasting with Google Trends in an Emerging Market. Journal of Forecasting, 32, 289-298. https://doi.org/10.1002/for.1252 
Center for Disease Control and Prevention (2021). Coronavirus Disease (COVID-19). https://www.cdc.gov/coronavirus/2019-ncov/index.html

Conover, M., Ratkiewicz, J., Francisco, M., Gonçalves, B., Menczer, F., \& Flammini, A. (2011). Political Polarization on Twitter. Proceedings of the Fifth International AAAI Conference on Weblogs and Social Media, 5, 89-96. https://ojs.aaai.org/index.php/ICWSM/article/view/14126

Davies, J. (1962). Toward a Theory of Revolution. American Sociological Association, 27, 5-19. https://doi.org/10.2307/2089714

della Porta, D. (2020). Protests as Critical Junctures: Some Reflections towards a Momentous Approach to Social Movements. Social Movement Studies, 19, 556-575. https://doi.org/10.1080/14742837.2018.1555458

Fischer, S. (1985). Supply Shocks, Wage Stickiness, and Accommodation. Journal of Money, Credit, and Banking, 17, 1-15. https://doi.org/10.2307/1992502

FRED (2020). Income and Poverty in the United States. (Unpublished) https://fred.stlouisfed.org/release?rid=249

FRED IC (2020). Initial Claims. https://fred.stlouisfed.org/series/ICSA

FRED UR (2020). Unemployment Rate. FRED. https://fred.stlouisfed.org/series/UNRATE

Freelon, D., McIlwain, C., \& Clark, M. (2018). Quantifying the Power and Consequences of Social Media Protest. New Media \& Society, 20, 990-1011. https://doi.org/10.1177/1461444816676646

Gourinchas, P. (2020). Flattening the Pandemic and Recession Curves (pp. 1-7). Working Paper, Princeton University.

Granger, C. (1969). Investigating Causal Relations by Econometric Models and Cross-Spectral Methods. Econometrica: Journal of the Econometric Society, 37, 424-438. https://doi.org/10.2307/1912791

Guerrieri, V., Lorenzoni, G., Straub, L., \& Werning, I. (2020). Macroeconomic Implications of COVID-19: Can Negative Supply Shocks Cause Demand Shortages? Tech. Rep., National Bureau of Economic Research. https://doi.org/10.3386/w26918

Hafner, C., \& Herwartz, H. (2009). Testing for Linear Vector Autoregressive Dynamics under Multivariate Generalized Autoregressive Heteroskedasticity. Statistica Neerlandica, 63, 294-323. https://doi.org/10.1111/j.1467-9574.2009.00424.x

Hamilton, J. (1994). Time Series Analysis. Princeton University Press. https://doi.org/10.1515/9780691218632

Hargittai, E., \& Walejko, G. (2008). The Participation Divide: Content Creation and Sharing in the Digital Age. Information, Communication and Society, 11, 239-256.

https://doi.org/10.1080/13691180801946150

Hyndman, R., \& Athanasopoulos, G. (2018). Chapter 8. ARIMA Models. In Forecasting: Principles and Practice (2nd ed.). OTexts. https://otexts.com/fpp2/arima.html

Jacobson, C., \& Choi, S. O. (2008). Success Factors: Public Works and Public-Private Partnerships. International Journal of Public Sector Management, 21, 637-657. https://doi.org/10.1108/09513550810896514

Korpi, W. (1974). Conflict, Power, and Relative Deprivation. The American Political Science Review, 68, 1569-1578. https://doi.org/10.2307/1959942

Krugman, P. (2020). Notes on the Coronacoma (Wonkish). The New York Times. https://www.nytimes.com/2020/04/01/opinion/notes-on-the-coronacoma-wonkish.html

Lebron, C. (2017). Making of Black Lives Matter: A Brief History of an Idea, Updated 
Edition. Oxford University Press.

McCarthy, J., \& Zald, M. (2001). The Enduring Vitality of the Resource Mobilization Theory of Social Movements. In J. H. Turner (Eds.), Handbook of Sociological Theory. Handbooks of Sociology and Social Research (pp. 533-565). Springer.

Miller, A., Bolce, L., \& Halligan, M. (1977). The J-Curve Theory and the Black Urban Riots: An Empirical Test of Progressive Relative Deprivation Theory. American Political Science Review, 71, 964-982. https://doi.org/10.1017/S0003055400265180

Mills, C. (1959). The Sociological Imagination. Oxford University Press. https://doi.org/10.2307/1891592

Mushtaq, R. (2011). Augmented Dickey Fuller Test. https://doi.org/10.2139/ssrn.1911068

Opp, K. (1988). Grievances and Participation in Social Movements. American Sociological Review, 53, 853-864. https://doi.org/10.2307/2095895

Penn State (2020). STAT 510 Applied Time Series Analysis. https://online.stat.psu.edu/stat510/

Pfaff, B. (2018). vars Package. https://www.pfaffikus.de/

Pfaff, B. (2020). VAR, SVAR and SVEC Models: Implementation within R Package Vars. cran.r.project.org.

Roper Center for Public Opinion Research (2020). Featured Datasets in Black Public Opinion. Tech. Rep.

https://ropercenter.cornell.edu/blog/featured-datasets-black-public-opinion

Rossi, W., \& Wang, Y. (2019) VAR-Based Granger-Causality Test in the Presence of Instabilities. https://www.crei.cat/wp-content/uploads/2019/03/GCrobust.pdf

Sen, A., \& Avci, Ö. (2016). Why Social Movements Occur: Theories of Social Movements. Journal of Knowledge Economy and Knowledge Management, 11, 125-130.

Sitler, D. (2020). Systemic Structural Racism to Blame for COVID-19's Uneven Toll on African Americans. Professional Staff Senate, University at Buffalo, University of Buffalo.

http://www.buffalo.edu/pss/news-home/gen news.host.html/content/shared/university Lnews/expert-tipsheets/2020/018.detail.html

Smelser, N. (1965). Theory of Collective Behavior. Free Press.

Smelser, N. (1988). Handbook of Sociology. Sage.

Suhoy, T. (2009). Query Indices and a 2008 Downturn: Israeli Data. Tech. Rep., Bank of Israel.

The Organization for Economic Cooperation and Development (2020). Shocks, Risks and Global Value Chains: Insights from the OECD METRO Model.

http://www.oecd.org/trade/documents/shocks-risks-gvc-insights-oecd-metro-model.pdf

Thurman, W. N., \& Fisher, M. E. (1988). Chickens, Eggs, and Causality. American Journal of Agricultural Economics, 70, 237-238. https://doi.org/10.2307/1242062

US Bureau of Labor Statistics (2020). Monthly Labor Review. https://www.bls.gov/opub/mlr/2020/article/demographics-earnings-and-family-charact eristics-of-workers-in-sectors-initially-affected-by-covid-19-shutdowns.htm

Van Dijcke, D., \& Wright, A. (2020). Using Mobile Device Traces to Improve Near-Real Time Data Collection during the George Floyd Protests. SSRN Electronic Journal. https://doi.org/10.2139/ssrn.3621731

Venables, W. N., \& Ripley, B. D. (2002). Modern Applied Statistics with S. Fourth. Springer. http://www.stats.ox.ac.uk/pub/MASS4

https://doi.org/10.1007/978-0-387-21706-2 
Weeber, S., \& Rodeheaver, D. (2003). Militias at the Millennium: A Test of Smelser's Theory of Collective Behavior. Sociological Quarterly, 44, 181-204. https://doi.org/10.1111/j.1533-8525.2003.tb00554.x

Zeileis, A. (2006). Object-Oriented Computation of Sandwich Estimators. Journal of Statistical Software, 16, 1-16. https://doi.org/10.18637/jss.v016.i09 